\title{
End-Of-Life Textiles as Reinforcements in Biocomposites
}

\author{
Sunil Kumar Ramamoorthy ${ }^{1,2}$ - Mikael Skrifvars ${ }^{1} \cdot$ Ragunathan Alagar $^{1}$ • \\ Naeem Akhtar ${ }^{1}$
}

Published online: 21 February 2017

(c) The Author(s) 2017. This article is published with open access at Springerlink.com

\begin{abstract}
A number of attempts have been made to recycle cotton/polyester blend woven fabrics after use; however, most of these fabrics are disposed of in landfills. Major part of these blend fabrics are not recycled due to complexity of the fibre arrangement and cannot be separated economically. This study shows that these discarded woven fabrics could be directly used as reinforcements in composites without fibre separation. Uniform alignment in the woven fabric provided consistent properties to the composites. The fabrics were reinforced by soybean-based-bioresins to produce biocomposites. The composites were analysed for mechanical, thermal, viscoelastic and morphological properties. Porosity and wettability of the composites were also evaluated. Results demonstrate that the tensile strength and modulus of over 100 and $10 \mathrm{MPa}$, respectively, can be obtained without any fibre treatment. Furthermore, impact strength over $70 \mathrm{~kJ} / \mathrm{m}^{2}$ was obtained without any chemical treatment on fibres. The porosity of the composites produced was less than 9 vol\%. Additionally, the fabrics were treated with alkali in order to improve the fibre-matrix interface and the composite properties were studied. From the economical perspective, these composites can be produced at a low cost as the major component is available for free or low cost.
\end{abstract}

Keywords Reuse $\cdot$ Textile composites $\cdot$ Mechanical properties $\cdot$ Porosity $\cdot$ Contact angle

Mikael Skrifvars

mikael.skrifvars@hb.se

1 Swedish Centre for Resource Recovery, University of Borås, 50190 Borås, Sweden

2 Swerea IVF, Box 104, 43122 Mölndal, Sweden

\section{Introduction}

There has been intense and vast research in developing renewable, novel, lightweight and environmentally friendly composite materials at low cost for automobile and construction applications [1-3]. Even though researchers have developed biocomposites from many natural fibres and renewable resource based plastics with good mechanical properties, a large quantity of non-renewable based polymers is used today in numerous applications including textiles $[4,5]$. Reusing valuable non-renewable resources efficiently contributes to sustainable living. Polyethylene terephthalate (PET) is widely used non-renewable petroleum based thermoplastic polymer that needs to be reused or recycled. In 2009, 31.9 million tonnes of polyester (PET) was consumed by global textile industry; 19.3 million tonnes was used to make filament yarns, and 12.6 million tonnes was used to make staple fibres. The amount of textile fibres production in 2011 reached a record high of 84.2 million tonnes, which is about $6 \%$ more than 2010 , according to recent data. The production of PET fibres will be the main and most reliable raw material base of global textile industry in next 5 years [6]. PET staple fibres are mostly used to produce cotton/PET blend fabrics, and these fabrics are regularly disposed of in the municipal waste that ends in landfills. PET blended fabrics are often disposed after its end-use due to complexity in recycling blended fabrics. The valuable non-renewable petroleum resource is wasted by dumping these fabrics in the landfills, which also creates environmental problems. Various methods are used to recycle pure PET products. Physical methods include melting of the PET bottles and making fibres from pure polymer, and chemical methods comprise the de-polymerization of PET [7, 8]. The above methods 
cannot be used to recycle PET blended fabrics because PET from fabrics can neither be separated mechanically nor by dissolving economically $[9,10]$. Moreover, a substantial amount of the energy put into the fabric is lost when the fibres are separated. The discarded fabrics can be effectively used as received, as reinforcements in composites, which not only avoids the downgrading of fibres but also gives good strength to the composites due to uniform alignment of the fibres. The project aims to reuse blended fabrics as reinforcement in composites.

This study is continuation of our previous paper where composites were produced from cotton/PET fabrics [9]. It is shown that composites from ecycled fabrics have good mechanical properties [9]. Zou et al. also produced composites from cotton/PET fabrics, and their properties were evaluated [10]. The above-mentioned studies were mostly based on thermoplastic composites, whereas the current study is based on thermoset composites. The study aims to produce composites from discarded fabrics and lab synthesised bioresin from soybean oil. The blended fabrics were reinforced by three different soybean oil based resins (acrylated epoxidised soybean oilAESO; methacrylated soybean oil-MSO and methacrylic anhydride modified soybean oil-MMSO) [11]. These bioresins were synthesised and characterised in our previous study [11]. The procedure is explained in the "Experimental" section. This concept is appealing both from resource management and economic aspects.

Mechanical and thermal properties were analysed using various tests. Water absorption of composites and their effect on mechanical properties were studied. Viscoelastic and morphological properties of the composites were investigated. Fibre-matrix interface and hydrophilicity were examined by porosity and contact angle measurements.

\section{Experimental}

\section{Materials}

Discarded cotton/PET (50:50) plain-weave fabrics were obtained from Textilia AB, Sweden. These fabrics have been used in hospitals, care centres and other institutions and had surface weight of $210 \mathrm{~g} / \mathrm{m}^{2}$. Envirez G 8600 INF60 resin was supplied by Ashland Inc, Finland. Acrylated epoxidised soybean oil (AESO) was supplied by Cogins $\mathrm{GmbH}$, Germany. Methacrylated soybean oil (MSO) and methacrylic anhydride modified soybean oil (MMSO) were synthesised as described in our previous study [11]. Free radical initiator, tert-butyl peroxy benzoate, was supplied by Aldrich Chemical Company, USA (Fig. 1).

\section{Fibre Treatment, Resin Synthesis, Resin Blending and Composite Preparation}

Dried cotton/PET fabrics were treated with sodium hydroxide solution for $2 \mathrm{~h}$ at different concentrations $(2,4,6,8$ and $10 \mathrm{wt} \%$ ) and then rinsed thoroughly with water for $\mathrm{pH}$ neutrality [12]. The fabrics were dried at room temperature before placing in oven at $105^{\circ} \mathrm{C}$ for $2 \mathrm{~h}$ to remove any moisture.

\section{MSO Synthesis}

Epoxidised soybean oil was stirred for $30 \mathrm{~min}$ in a three neck round bottom flask with a magnetic stirrer. Methacrylic acid containing $0.25 \mathrm{wt} \%$ of hydroquinone was added and constantly mixed for $8 \mathrm{~h}$ at $120^{\circ} \mathrm{C}$. Excess methacrylic acid containing $4 \mathrm{mg}$ of hydroquinone was later added, and reaction continued for another $4 \mathrm{~h}$. After the reaction, the mixture was allowed to cool to room temperature and purified by extraction and then isolated using a rotary evaporator.

\section{MMSO Synthesis}

MSO was dissolved in chloroform in a three neck round bottom flask, being constantly stirred and heated under reflux condenser at $55^{\circ} \mathrm{C}$. Methacrylic anhydride was added dropwise for $15 \mathrm{~min}$ after which the temperature was raised to $60^{\circ} \mathrm{C}$. $N$-methylimidazol of $1 \mathrm{wt} \%$ was used as a catalyst, and the reaction proceeded for $3 \mathrm{~h}$. After the reaction, the mixture was allowed to cool to room temperature, extracted and isolated using a rotary evaporator.

Viscosity of resin influences the fibre impregnation; therefore, the resin was heated at $60^{\circ} \mathrm{C}$ for $5 \mathrm{~min}$ before mixing with the initiator. Envire ${ }^{\mathrm{TM}}$ and soybean based resins were mixed with 1 and $2 \mathrm{wt} \%$ initiator respectively.

The woven fabrics were cut to $20 \mathrm{~cm} \times 20 \mathrm{~cm}$ swatches and dried in oven at $105^{\circ} \mathrm{C}$ for $1 \mathrm{~h}$ before resin impregnation. The composites with different fibre-matrix ratio were produced by placing alternate layers of reinforcement and matrix in compression moulding (Hydraulic hot press, Rondol Technology, UK) for 5 min, Table 1. Woven fabrics were stacked according to cloth stacking sequence, where the warp face of one ply is in contact with the corresponding ply fill face. The pressure ( 25 bar) was maintained constant for all composites, whereas the temperature was $120^{\circ} \mathrm{C}$ for Envirez ${ }^{\mathrm{TM}}$ and $160^{\circ} \mathrm{C}$ for soybean oil based resins. Weight fraction was used, as weight is easy to control in the manufacturing procedure. Volume fraction was calculated during density and porosity measurements.

The specimens for each testing were cut from the laminates using laser technology (GCC LaserPro Spirit). The specimens were cut according to the standards mentioned 
Fig. 1 a Chemical structure of AESO, $\mathbf{b}$ chemical structure of MSO, $\mathbf{c}$ chemical structure of MMSO

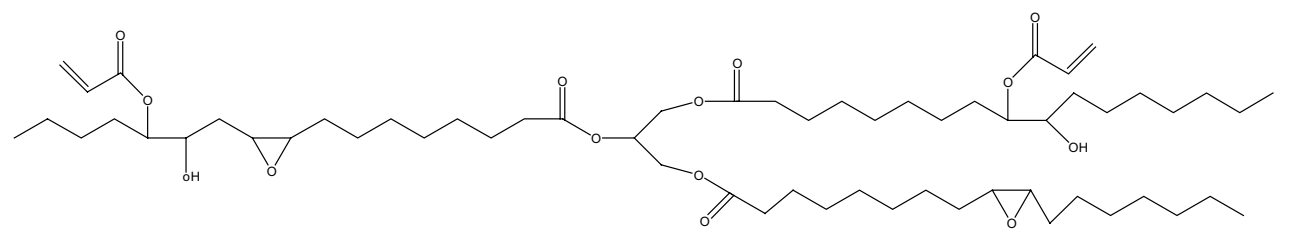

(a)

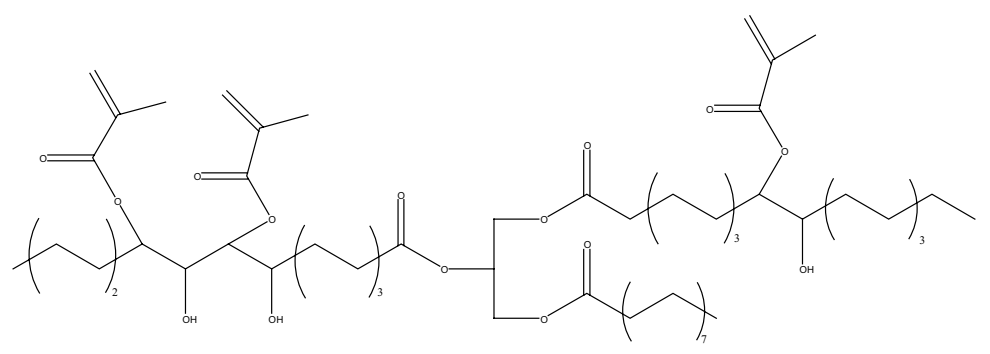

(b)

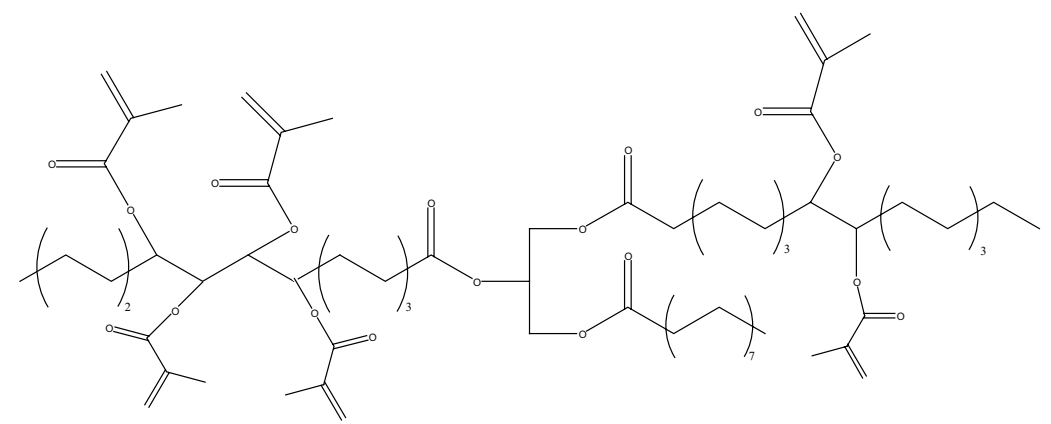

(c)
Table 1 Composites and their processing parameters

\begin{tabular}{|c|c|c|c|c|}
\hline Reinforcement treatment & Resin & $\begin{array}{l}\text { Initiator* } \\
(\mathrm{wt} \%)\end{array}$ & Fibre-Resin ratio & $\begin{array}{l}\text { Molding } \\
\text { temperature } \\
\left({ }^{\circ} \mathrm{C}\right)\end{array}$ \\
\hline Untreated & Envirez $^{\mathrm{TM}}$ & 1 & $\begin{array}{l}50: 50,60: 40,40: 60, \\
55: 45,45: 55,65: 35\end{array}$ & 120 \\
\hline Untreated & AESO, MMSO, MSO & 2 & $40: 60,50: 50,60: 40$ & 160 \\
\hline $\begin{array}{l}\mathrm{NaOH} \text { treated woven }(2,4, \\
6,8,10 \mathrm{wt} \%)\end{array}$ & Envirez $^{\mathrm{TM}}$ & 1 & $50: 50$ & 120 \\
\hline
\end{tabular}

The compression time and pressure was $10 \mathrm{~min}$ and $100 \mathrm{kPa}$ respectively

*The initiator was tert-butyl peroxy benzoate in the "Characterisation" section of this article. The edge effects were minimised by taking the specimens from the laminate centre.

\section{Characterisation}

Mechanical, thermal, viscoelastic and morphological analyses were done to study the performance of the composites. Mechanical properties are characterised by tensile, flexural and impacts tests, whereas thermal properties were studied by differential scanning calorimetry and thermogravimetric analysis. Density, porosity and water absorption were also investigated.

MSO and MMSO bioresins have been characterised in our earlier study [11]. Viscosity and cure investigations were performed [11]. 


\section{Mechanical Testing}

Tensile testing was carried out according to the standard for determination of tensile properties (ISO 527) using a Tinius Olsen H10KT universal tester. An extensometer was used to measure the strain. Load cell capacity was $5000 \mathrm{~N}$, and the loading rate was $10 \mathrm{~mm} / \mathrm{min}$. Dry and water-soaked (7 days) specimens were tested for tensile properties. At least ten dog-bone shaped specimens were analysed for each sample, and the mean values were reported. Tensile strength, Young's modulus and elongation were examined.

Three-point flexural testing was carried out according to the standard for Determination of Flexural Properties (ISO 14125) with the same testing equipment Tinius Olsen H10KT universal tester as for tensile testing. The load range was $5000 \mathrm{~N}$, displacement range was $10 \mathrm{~mm}$, test speed was $4 \mathrm{~mm} / \mathrm{min}$, span was $64 \mathrm{~mm}$, strain was $10 \%$ and approach speed was $10 \mathrm{~mm} / \mathrm{min}$. The mean values were reported from at least ten specimens from each sample. Flexural strength and modulus were studied.

Charpy impact test was performed according to the standard for determination of Charpy impact properties (ISO 179) using Zwick test instrument. The pendulum used to perform the test was of 5 Joules energy. At least ten unnotched specimens were tested flatwise for each sample, and the mean impact resistance was determined.

\section{Thermal Analysis}

Differential scanning calorimetry (DSC Q2000) from TA Instruments, USA was used to analyse thermal properties of the resins and the composites. The temperature range was 30 to $300^{\circ} \mathrm{C}$ with a heating rate of $10^{\circ} \mathrm{C} / \mathrm{min}$. There were two heating ramps and one cooling ramp. The experiment was done under nitrogen atmosphere. The sample size was approximately $10 \mathrm{mg}$. Glass transition temperature $\left(\mathrm{T}_{\mathrm{g}}\right)$, curing of resins and exothermic peaks were noted. At least three specimens were tested for each sample.

Thermogravimetric analysis (TGA Q500) from TA instruments, USA was used to analyse thermal stability of the composites. Approximately $15 \mathrm{mg}$ of the samples was heated from 30 to $600^{\circ} \mathrm{C}$ at $10^{\circ} \mathrm{C} / \mathrm{min}$ in a nitrogen purge stream. The flow of nitrogen was $50 \mathrm{~mL} / \mathrm{min}$. At least two specimens were tested for each sample.

\section{Viscoelastic Analysis}

Dynamic mechanical thermal analysis (DMA Q800) from TA instruments, USA was used to study viscoelastic properties of the composites. A single cantilever clamp was used to perform the tests. The amplitude was $15 \mu \mathrm{m}$, and the frequency was $1 \mathrm{~Hz}$. The length of the samples was $17.5 \mathrm{~mm}$, but the thickness and width varied with composites. Three specimens from each composite were tested.

\section{Water Absorption}

Water absorption tests were carried out to study the determination of water absorption of the composites (ISO 62) by the function of time. This test can be indirectly related to the porosity of the composites. The specimens were first dried in oven at $105^{\circ} \mathrm{C}$ for $24 \mathrm{~h}$, and then their weights are measured and noted as $\mathrm{W}_{0}$. Five specimens for each sample were then immersed in distilled water. The specimens were then padded with tissue paper and weighed, $\mathrm{W}$. The amount of water absorbed was measured every $24 \mathrm{~h}$ for 7 days. After weighing, they were returned to the distilled water. The following formula was used to calculate the percentage water absorption (WA \%).

$W A \%=\frac{W-W_{o}}{W_{o}} \times 100$

\section{Porosity and Composite Density}

Archimedes' principle was used to determine the densities of the composites by the buoyancy method. Ethanol was used as the displacement medium. The samples were dried in oven at $105^{\circ} \mathrm{C}$ for $1 \mathrm{~h}$ to make it moisture free and then immersed in liquid paraffin in order to make a layer of paraffin around the samples to avoid absorption of displacement medium. The fibre weight fraction with allowance for porosity was used to calculate the fibre volume fraction. This method has been described by Madsen at al. and has been adopted successfully in previous research $[13,14]$.

\section{Contact Angle}

Static contact angle measurements were performed using Attension Theta Instrument supplied by Biolin Scientific to examine the wettability of the composites. A drop of probe liquid, deionised water was placed on the specimen, and the image was captured through high resolution digital camera to further analyse in OneAttension software.

\section{Morphological Analysis}

Morphological analysis was done using Nikon optical microscope. The cross sections of the tensile-fractured composite specimens were studied to see the fibre-matrix interfaces and the fibre pull-out. 


\section{Results and Discussion}

\section{Mechanical Properties}

Table 2 shows the results from all the mechanical tests (tensile, flexural and impact tests) of different composite types (matrix, fibre weight $\%$ and alkali treatment).

\section{Tensile Properties}

Tensile properties (tensile strength, E-modulus and elongation \%) of the composites are tabulated (Table 2), and it shows that the waste fabric reinforced composites' tensile properties such as tensile strength and E-modulus can be compared to several natural fibre composites [4, 15]. E-modulus of the mentioned natural fibre composites was between 4 and $10 \mathrm{GPa}$, while the tensile strength of the same composites was between 25 and $100 \mathrm{MPa}$ [15]. Young's modulus over $10 \mathrm{GPa}$ was obtained when the fabric was used directly without any chemical treatment. This was due to the tensile properties of the individual fibres in the fabric, uniform arrangement of the fibres in the fabric, high modulus of the Envirez ${ }^{\mathrm{TM}}$ bio-based resin and the good fibre-matrix compatibility. Tensile strength and modulus of commercial polyester (Envirez ${ }^{\mathrm{TM}}$ ) based composites were higher than that of lab synthesised soybean based bioresins. Lab synthesised bioresins were brittle and were more susceptible to failure than Envirez ${ }^{\mathrm{TM}}$ matrix. Tensile strength and modulus of Envirez ${ }^{\mathrm{TM}}$ composites were $111.7 \mathrm{MPa}$ and $11.4 \mathrm{GPa}$ when fibre wt\% in the composites was 50 , whereas MMSO based composites have highest tensile properties among soybean matrix based composites with tensile strength of $76.2 \mathrm{MPa}$ and 5.5 GPa. MMSO based composites have better tensile properties than that of MSO based composites, which was expected from our previous results [16]. AESO based composite properties were comparable to other soybean based resins. Tensile strength and modulus of all the composites increased with an increase in fibre amount from 40 to $50 \mathrm{wt} \%$; highest increase was noticed in Envirez ${ }^{\mathrm{TM}}$ composites with more than $30 \%$ increase in tensile strength. The increase is mainly due to higher strength of the reinforcement than the matrix used and uniform distribution of reinforcement fibres in the fabric. Composites were also produced with up to $65 \mathrm{wt} \%$ fibre but the mechanical properties of the composites did not increase significantly. On visual examination, we noticed that some sections of the composites were not wetted thoroughly. This uneven distribution was due to high fibre content and insufficient matrix in the composites. Uneven distribution of the matrix in the composites led to the early failure of the matrix and eventually no significant increase in mechanical properties on addition of the fibres (fibres were deformed but did not break before the failure of the matrix). Similar results were noticed in cellulose based composites, and the tensile properties decreased due to brittleness of thermoset matrix $[9,17]$. Modulus could suggest
Table 2 Mechanical properties of the composites (tensile, flexural and impact properties)

\begin{tabular}{|c|c|c|c|c|c|}
\hline $\begin{array}{l}\text { Sample conditions } \\
\text { (Fibre:Resin) }\end{array}$ & Tensile strength $[\mathrm{MPa}]$ & $\begin{array}{l}\text { Young's } \\
\text { modulus } \\
{[\mathrm{GPa}]}\end{array}$ & $\begin{array}{l}\text { Flexural } \\
\text { strength } \\
{[\mathrm{MPa}]}\end{array}$ & $\begin{array}{l}\text { Flexural } \\
\text { modulus } \\
{[\mathrm{GPa}]}\end{array}$ & $\begin{array}{l}\text { Impact } \\
\text { strength } \\
{\left[\mathrm{kJ} / \mathrm{m}^{2}\right]}\end{array}$ \\
\hline \multicolumn{6}{|l|}{ Untreated fibre } \\
\hline Envirez $^{\mathrm{TM}}(50: 50)$ & $111.7 \pm 6.6$ & $11.4 \pm 2.2$ & $62.5 \pm 3.3$ & $4.3 \pm 0.8$ & $61.0 \pm 2.1$ \\
\hline $\operatorname{AESO}(50: 50)$ & $72.6 \pm 5.2$ & $5.3 \pm 0.6$ & $46.0 \pm 3.7$ & $2.4 \pm 0.6$ & $53.0 \pm 2.0$ \\
\hline $\operatorname{MSO}(50: 50)$ & $64.1 \pm 0.9$ & $4.6 \pm 1.5$ & $57.7 \pm 5.8$ & $4.6 \pm 1.2$ & $49.0 \pm 1.7$ \\
\hline $\operatorname{MMSO}(50: 50)$ & $76.2 \pm 4.2$ & $5.5 \pm 0.6$ & $59.2 \pm 3.7$ & $3.5 \pm 1.0$ & $70.5 \pm 1.9$ \\
\hline \multicolumn{6}{|c|}{ Untreated Fibre:Envirez ${ }^{\mathrm{TM}}$} \\
\hline $40: 60$ & $82.9 \pm 4.5$ & $8.5 \pm 0.3$ & $52.4 \pm 1.8$ & $4.0 \pm 1.0$ & $78.2 \pm 2.1$ \\
\hline $50: 50$ & $111.7 \pm 6.6$ & $11.4 \pm 2.2$ & $62.5 \pm 3.3$ & $4.3 \pm 0.8$ & $61.0 \pm 2.1$ \\
\hline \multicolumn{6}{|c|}{ Untreated Fibre:MSO } \\
\hline $40: 60$ & $60.6 \pm 3.8$ & $3.7 \pm 1.4$ & $49.2 \pm 3.7$ & $3.9 \pm 0.7$ & $50.3 \pm 2.2$ \\
\hline $50: 50$ & $64.1 \pm 0.9$ & $4.6 \pm 1.5$ & $57.7 \pm 5.8$ & $4.6 \pm 1.2$ & $49.0 \pm 1.7$ \\
\hline \multicolumn{6}{|c|}{ Untreated Fibre:MMSO } \\
\hline $40: 60$ & $60.2 \pm 2.0$ & $4.1 \pm 1.7$ & $49.1 \pm 5.4$ & $3.5 \pm 1.4$ & $75.2 \pm 2.1$ \\
\hline $50: 50$ & $76.2 \pm 4.2$ & $5.5 \pm 0.6$ & $59.2 \pm 3.7$ & $3.5 \pm 1.0$ & $70.5 \pm 1.9$ \\
\hline \multicolumn{6}{|c|}{ Treated Fibre:Envirez ${ }^{\mathrm{TM}}(50: 50)$} \\
\hline $2 \mathrm{wt} \%$ alk. conc & $71.7 \pm 4.5$ & $9.0 \pm 1.6$ & $76.9 \pm 5.5$ & $3.8 \pm 1.1$ & $48.9 \pm 1.9$ \\
\hline $4 \mathrm{wt} \%$ alk. conc & $64.2 \pm 3.7$ & $7.5 \pm 1.1$ & $74.3 \pm 5.6$ & $3.6 \pm 1.5$ & $56.5 \pm 2.0$ \\
\hline $8 \mathrm{wt} \%$ alk. conc & $61.0 \pm 1.3$ & $8.7 \pm 1.5$ & $81.5 \pm 5.3$ & $4.6 \pm 1.8$ & $54.0 \pm 2.1$ \\
\hline
\end{tabular}


the toughness of the composites; high moduli of polymer composites in many cases indicate less tough materials [11, 18]. Toughness of the composites is discussed with impact properties.

The elongation was less than $2.5 \%$ for all the composites. The elongation of the composites decreased on increasing the amount of fibre in the composites in contrast to the modulus of the composites. This decrease in the elongation and simultaneous increase in the modulus on increasing in the fibre amount is directly related to the plastic behaviour of individual components. Thermoset matrices showed more plastic behaviour than the reinforcement in all cases.

Our former study showed that soybean matrix based composites had tensile strength between 50 and $150 \mathrm{MPa}$ at 40-60 wt\% fibre loading $[17,19]$. Tensile modulus of the composites was between 6 and $17 \mathrm{GPa}$ and the elongation was between 1.6 and $2.6 \%$ which falls in line with the results from this study $[17,19]$.

\section{Flexural Properties}

Flexural properties followed similar trend as the tensile properties, Table 2 . The flexural strength and the modulus increased on increasing the amount of the fibre from 40 to $50 \mathrm{wt} \%$ in the composite. Envirez ${ }^{\mathrm{TM}}$ based composites had higher flexural strength (62.5 MPa) and modulus (4.3 GPa) than that of composites based on soybean based matrix. However, flexural strength (59.2 MPa) of MMSO based composite was not significantly different from Envirez ${ }^{\mathrm{TM}}$ composite $(62.5 \mathrm{MPa})$ when the standard deviation was considered. The flexural properties such as flexural strength and flexural modulus of recycled fabric reinforced composites can be compared to several natural fibre composites, Table $2[4,15]$.

\section{Impact Properties}

Table 2 shows the results from Charpy impact test. Impact strength indicates the energy absorbed by the composite specimen during fracture. Impact strength of the composites was between 45 and $80 \mathrm{~kJ} / \mathrm{m}^{2}$; which is usually the case for natural fibre reinforced composites $[4,15]$. Envirez ${ }^{\mathrm{TM}}$ based composites absorbed more energy during fracture than that of composites from soybean based matrix. Highest impact strength obtained was $78.2 \mathrm{~kJ} / \mathrm{m}^{2}$, which can be compared to flax/hemp fibre reinforced biocomposites [4, 15]. Similar results were obtained in our preceding study where composites were produced by reinforcing cotton/ PET waste fabrics in thermoset and thermoplastic matrices [9]. Toughness of the composites can be improved by reinforcing the waste fabrics in less brittle matrices and/or by inclusion of plasticizers.

\section{Effect of Alkali Treatment on Mechanical Properties}

Fabrics were treated with different alkali concentrations in order to improve the fibre-matrix interface and the mechanical properties. In contrast, the mechanical properties of the composites decreased at all alkali concentrations, which could be due to uneven thinning of the fibre in the aligned fabric. Hydrolysis of polyester in the reinforcement fabric could also be the reason for the decrease in the mechanical properties. Alkali broke the ester linkages and formed ethane 1,2 diol together with carboxylic acid salt.

Alkali treatment may possibly affect the composite properties in humid conditions as the surface treatment brings matrix closer to the fibre and reduces the water penetration. This was studied and reported in later in this article. Alkali treatment on cellulose fibres was studied in detail in our former studies $[12,20]$.

\section{Thermal Properties}

\section{Differential Scanning Calorimetry (DSC)}

DSC analysis showed the crosslinking reaction efficiency of the resin at the specified curing conditions. Exothermic peak occurred in the first heating scan when the resin mixed with the initiator was placed in DSC with the mentioned composited manufacturing factors (temperature and time). This confirms the exothermic curing reaction at the specified conditions. No exothermic peak was seen in the second heating scan when the cured resin was heated in DSC. This meant that the resin was cured completely during the scan. This was confirmed using FTIR spectra, as there were no carbon-carbon double bonds [11]. Exothermic heats evolved from uncured MSO and MMSO were 36.77 and $34.57 \mathrm{~J} / \mathrm{g}$, respectively [11]. Figure 2 shows the DSC curves of AESO and MSO resins when mixed with $2 \mathrm{wt} \%$ tert-butyl peroxy benzoate initiator, where the first heating scan released exothermic heat and the second heating scan did not release any heat which ratifies the curing. Composite samples were also run in DSC, and the curves showed no exothermic heat released which confirms complete curing of the bioresins during composite manufacturing. Therefore, the post-curing of the composite samples was ignored. The glass transition of the AESO, MSO and MMSO were between 80 and $90^{\circ} \mathrm{C}$, and this was also confirmed in dynamic mechanical thermal analysis (reported on later in this article).

\section{Thermogravimetric Analysis (TGA)}

Thermal decomposition resistance of the bioresins and the composites were evaluated by studying the gravimetric 
Fig. 2 DSC curves of AESO and MSO resins with $2 \mathrm{wt} \%$ tert-butyl peroxy benzoate initiator

Fig. 3 TGA curves of the composites from different resins with $50 \mathrm{wt} \%$ reinforcement
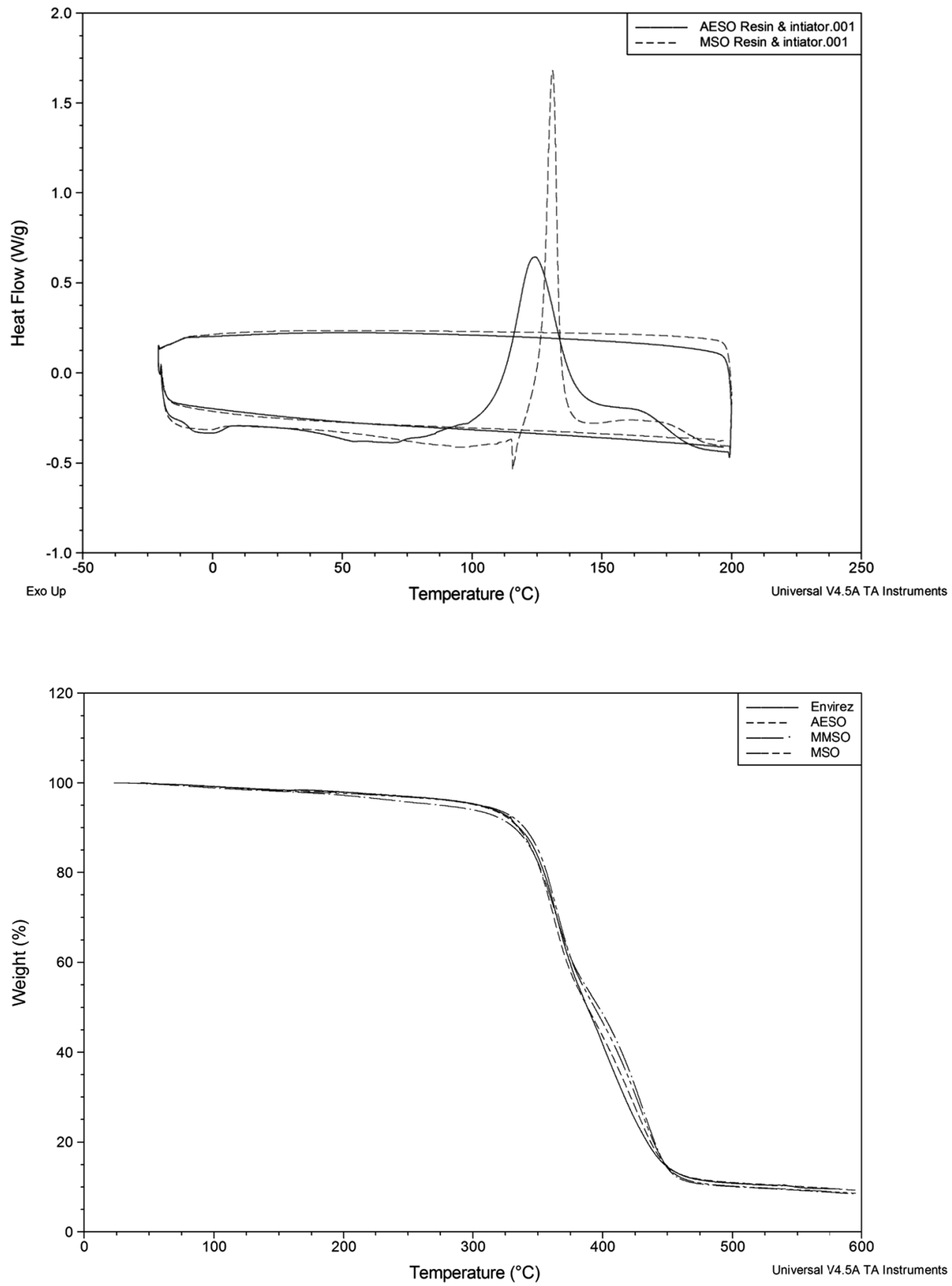

weight loss with the function of temperature. Thermal degradation of the cured resins (MSO and MMSO) occurred in the temperature region $320-480^{\circ} \mathrm{C}$. Figure 3 shows the TGA curves of the composites from different resins with $50 \%$ reinforcement, and all the composites behave in the same manner. The resins and the composites were relatively stable up to $300^{\circ} \mathrm{C}$, while the addition of reinforcement to the resins changed the thermal stability slightly as anticipated [20].

Initial loss in the composites could be attributed to moisture in the cotton-based reinforcement. The temperature at which $90 \%$ of the material is lost was increased from about $480^{\circ} \mathrm{C}$ in the resin to about $500^{\circ} \mathrm{C}$ in the composites. This increase was mainly due to the residual ash from high amount of reinforcement in the composites. Second derivative curves of the composites showed two peaks, which correspond to the reinforcement and the resin degradation. This was interesting as it revealed that the cellulose degradation in the reinforcement shifted on alkali treatment. Similar trends were obtained from the composites produced from regenerated cellulose fibres [20]. 


\section{Viscoelastic Properties}

\section{Dynamic Mechanical Thermal Analysis (DMTA)}

Viscoelastic properties of the composites were studied using DMTA curves. Storage modulus of the Envirez ${ }^{\mathrm{TM}}$ composite was $3985 \mathrm{MPa}$ at $35^{\circ} \mathrm{C}$ when the amount of reinforcement in the composites was $50 \mathrm{wt} \%$. There was a surge in the storage modulus on increasing the amount of the reinforcement in the composites. This was due to the increase in the stiffness of the composites. Storage modulus of the cured resin corresponds to the polymer chain packing density in the glassy state. The movements of the chain segments are restricted due to high cross-linking density [20].

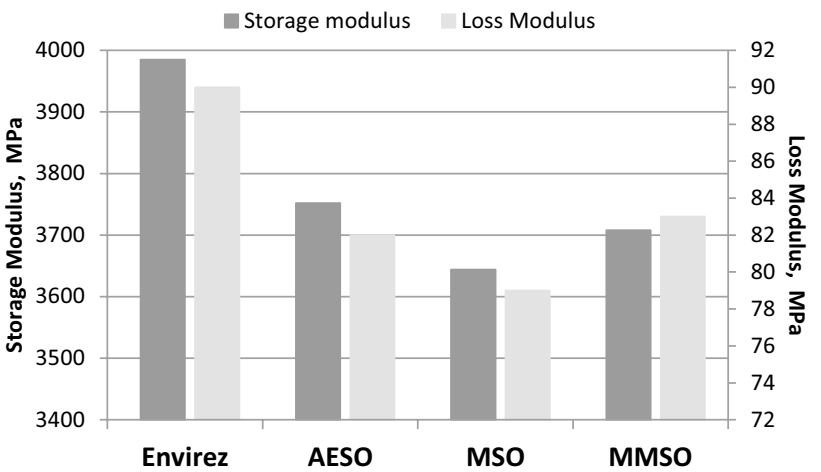

Fig. 4 Storage and loss modulus of the composites from different resins with $50 \mathrm{wt} \%$ reinforcement in $\mathrm{MPa}$ at $35^{\circ} \mathrm{C}$ from DMTA curves
AESO based composites had higher storage modulus than that of MSO and MMSO composites, and the alkali treatment to the reinforcement did not increase the storage modulus of the composites. These results fall in line with the mechanical properties. Loss modulus of the composites followed the same trend while the values were lower than $100 \mathrm{MPa}$, which indicates the low viscous response of the composites and could be overcome by addition of small amount of plasticizers (Fig. 4).

Glass transition temperature, $T_{g}$, was obtained from the $\tan \delta$ curve, and the $\mathrm{T}_{\mathrm{g}}$ of the composites were between 80 and $100^{\circ} \mathrm{C}$ (See Fig. 5). $\mathrm{T}_{\mathrm{g}}$ obtained from DMTA was slightly higher than that of $\mathrm{T}_{\mathrm{g}}$ from DSC, and a similar trend was noticed in our previous research [20]. This was mainly due to DMTA sensitivity towards the glass transition temperature. The glass transition temperature increased slightly on addition of reinforcement to the resin, as it restricted the mobility of the polymer chains in the interface. This phenomenon was observed previously by several authors $[18,21]$.

\section{Water Absorption}

Table 3 shows the amount of water absorbed by the composites when the specimens were completely immersed in the water for a specific period and the effect of water absorption on tensile properties. Water absorption of cotton/PET fabric reinforced composites is inevitable unless the cotton blend fabric is shielded completely, as cellulose absorbs water readily. The composites were submerged and the water absorption was followed every $24 \mathrm{~h}$ for 7 days. The absorption was more pronounced for the first 4 days,
Fig. 5 Tan delta of the composites from different resins with $50 \mathrm{wt} \%$ reinforcement

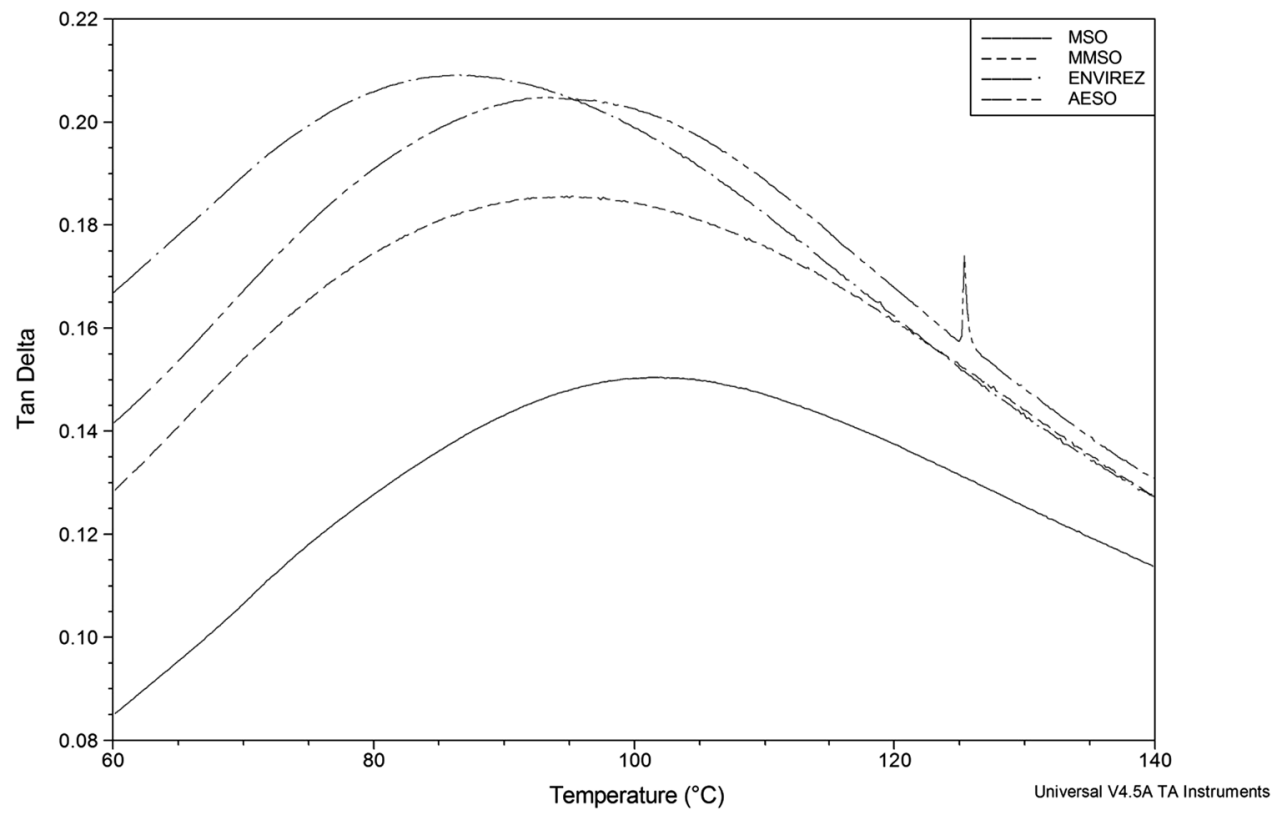


Table 3 Water absorption of the composites and their corresponding tensile properties

\begin{tabular}{|c|c|c|c|}
\hline \multirow[t]{2}{*}{$\begin{array}{l}\text { Sample conditions } \\
\text { (Fibre:Resin) }\end{array}$} & \multirow{2}{*}{$\begin{array}{l}\text { Water } \\
\text { absorption } \\
\text { (wt } \% \text { ) }\end{array}$} & \multicolumn{2}{|c|}{$\begin{array}{l}\text { Tensile properties after water } \\
\text { absorption }\end{array}$} \\
\hline & & $\begin{array}{l}\text { Tensile strength } \\
{[\mathrm{MPa}]}\end{array}$ & $\begin{array}{l}\text { Young's } \\
\text { modulus } \\
{[\mathrm{GPa}]}\end{array}$ \\
\hline \multicolumn{4}{|l|}{ Untreated fibre } \\
\hline Envirez $^{\mathrm{TM}}(50: 50)$ & 5.9 & $57.4 \pm 10.3$ & $4.2 \pm 0.9$ \\
\hline AESO (50:50) & 6.9 & $66.1 \pm 2.1$ & $2.9 \pm 0.6$ \\
\hline $\operatorname{MSO}(50: 50)$ & 9.1 & $53.2 \pm 2.3$ & $2.5 \pm 1.1$ \\
\hline MMSO (50:50) & 6.9 & $63.4 \pm 3.0$ & $2.5 \pm 0.7$ \\
\hline \multicolumn{4}{|c|}{ Untreated Fibre:Envirez ${ }^{\mathrm{TM}}$} \\
\hline $40: 60$ & 5.0 & $53.8 \pm 5.1$ & $3.6 \pm 0.4$ \\
\hline $50: 50$ & 5.9 & $57.4 \pm 10.3$ & $4.2 \pm 0.9$ \\
\hline \multicolumn{4}{|c|}{ Untreated Fibre:MSO } \\
\hline $40: 60$ & 7.8 & $48.4 \pm 3.0$ & $2.1 \pm 1.0$ \\
\hline $50: 50$ & 9.1 & $53.2 \pm 2.3$ & $2.5 \pm 1.1$ \\
\hline \multicolumn{4}{|c|}{ Untreated Fibre:MMSO } \\
\hline 40:60 & 5.6 & $48.3 \pm 2.5$ & $2.4 \pm 1.1$ \\
\hline $50: 50$ & 6.9 & $63.4 \pm 3.0$ & $2.5 \pm 0.7$ \\
\hline \multicolumn{4}{|c|}{ Alkali treated Fibre:Envirez ${ }^{\mathrm{TM}}(50: 50)$} \\
\hline $2 \mathrm{wt} \%$ alk. conc & 6.0 & $61.4 \pm 1.6$ & $4.5 \pm 2.2$ \\
\hline $4 \mathrm{wt} \%$ alk. conc & 5.7 & $55.1 \pm 4.9$ & $3.9 \pm 1.6$ \\
\hline $8 \mathrm{wt} \%$ alk. conc & 4.1 & $54.0 \pm 2.3$ & $3.3 \pm 1.3$ \\
\hline
\end{tabular}

as observed previously with cellulose fibre reinforced composites $[19,20]$. The water absorption of the composites was primarily influenced by the reinforcement. Absorption could also be influenced by various factors such as diffusion of water molecules between polymer chains, into the pores and into the fibre-matrix interface. For that reason, it is necessary to use less hydrophilic fibres and a resin with high cross-linking density. MSO based composites absorbed the highest amount of water, whereas Envirez ${ }^{\mathrm{TM}}$ based composites absorbed the least. This could be attributed to end groups of the matrices and their interaction with the reinforcement and the water. Alkali treatment on reinforcement surface reduced the water absorption from 5.9 to $4.1 \mathrm{wt} \%$ when the alkali concentration was $8 \mathrm{wt} \%$. This was due to better fibre-matrix interface that reduced the water penetration. As a result, the pore volume was also decreased. This also means that there could have been severe damage to the fibres as the alkali concentration was $8 \%$, which is reflected in tensile properties. Previous studies showed a similar trend when the cellulose fibre was treated with alkali $[12,20]$.

Tensile strength and modulus of all the composites reduced due to water absorption as expected; nevertheless, it followed a similar trend to that of composites before water absorption. As water was primarily absorbed by the cotton reinforcement, it widened the interface and generated new stress on the matrix. This stress could initiate a crack that propagates easily during tensile testing. The reduction of tensile properties was lower when the reinforcement was treated with $2 \mathrm{wt} \%$ alkali concentration, whereas the higher alkali concentration lowered the tensile strength and the modulus. Alkali treatment improved the fibre's interaction with the matrix, but fibre thinning occurred at low alkali concentration. This reduced the tensile properties of the composites. Tensile strength and modulus of the composites decreased at high alkali concentration despite the reduction in the water uptake, which could be due to severe fibre damage at high alkali concentration. These results can be compared to previous research where alkali treated cellulose fibres were reinforced in bioresins $[12,20]$.

\section{Porosity and Composite Density}

Several factors such as resin penetration, resin viscosity and composite manufacturing process affect the composite porosity. All the resins were pre-heated before impregnating as mentioned earlier owing to the probability that the viscosity of the resins affects the porosity of the composites. These air filled cavities are difficult to avoid in the composite due to mixing of different materials, such as different viscosity resins and dense reinforcements. The summary of density and porosity measurements of the composites are presented in Table 4 . The porosity volume of the composites was between 3 and 9 vol\%. As discussed before, the tensile strength of the composites increased on increasing the amount of fibre in the composites; at the same time, it could also increase the pore volume due to improper fibre wetting [20]. This results in delamination of the layers when stress is applied and subsequent composite failure occurs [20]. Envirez ${ }^{\mathrm{TM}}$ composites had highest pore volume among the composites produced with $8.8 \mathrm{vol} \%$. Alkali treatments on reinforcements reduced the pores slightly due to the reasons mentioned earlier, and these results are in good agreement with the results from water absorption.

\section{Contact Angle}

The hydrophilicity of the composites is directly related to the polarity of the reinforcement and the matrix. High contact angle value of the composite indicates that the absence of polar groups or the groups are not accessible by the water molecule. There is an interaction of the polar and the dispersive parts when a liquid comes in contact with a solid surface at interface. The surface tension at the interface is higher than the total surface tension of the solid and the liquid phase due to interactions at the interface [12]. Table 5 shows the surface energy components of the probe liquids used. The contact angle 
$(\theta)$ is a function of the solid's surface energy and the liquid's surface tension and was measured using the above mentioned probe liquids. An angle below $90^{\circ}$ represents the wetting of the solid phase whereas an angle above $90^{\circ}$ represents the non-wettability [18].

Table 6 shows the contact angles of the composites from four probe liquids. All the composites had contact angle lower than $90^{\circ}$, which meant all the composites are hydrophilic and confirms the results from water absorption. Alkali treatments on reinforcements increased the contact angle values slightly, which could be due to good interlocking of matrix with fibres. The reason for the change in the contact angles among AESO, MSO and MMSO composites could be the interaction of the probe liquids with matrix.

\section{Morphological Properties}

Figure 6 shows the optical microscopy images of the tensile fractured specimens before water absorption. These images were taken in order to examine the layers in the laminate. Fibre pull-out was seen in the Envirez ${ }^{\mathrm{TM}}$ composite specimens (Fig. 6a) that had untreated reinforcement, whereas this pull-out was less pronounced when the reinforcements were treated with alkali. MMSO composites had a sharp break (low fibre pull-out) accompanied with delamination (Fig. 6b), and similar effect was seen in MSO composites. This could have reduced the mechanical properties of the composites. Improper fibre wetting, insufficient matrix and wide polarity difference between reinforcement and the matrix could result in delamination, which can be minimised by using established fibre treatments or coupling
Table 4 Density and porosity of the composites with different resins

\begin{tabular}{lclll}
\hline $\begin{array}{l}\text { Sample conditions } \\
\text { (Fibre:Resin=50:50) }\end{array}$ & $\begin{array}{l}\text { Density }\left(\mathrm{g} \mathrm{cm}^{-3}\right) \\
{[\mathrm{MPa}]}\end{array}$ & $\begin{array}{l}\text { Fibre volume frac- } \\
\text { tion [\%] }\end{array}$ & $\begin{array}{l}\text { Matrix volume } \\
\text { fraction [\%] }\end{array}$ & $\begin{array}{l}\text { Porosity vol- } \\
\text { ume fraction } \\
{[\%]}\end{array}$ \\
\hline $\begin{array}{l}\text { Untreated fibre reinforced composites } \\
\text { Envirez }\end{array}$ & $1.15 \pm 0.09$ & $39.5 \pm 1.8$ & $60.5 \pm 1.5$ & $8.8 \pm 1.10$ \\
AESO & $1.27 \pm 0.04$ & $43.3 \pm 2.2$ & $56.7 \pm 2.8$ & $3.8 \pm 0.46$ \\
MSO & $1.26 \pm 0.10$ & $43.2 \pm 2.3$ & $56.8 \pm 1.3$ & $4.8 \pm 0.87$ \\
MMSO & $1.29 \pm 0.08$ & $39.7 \pm 2.7$ & $60.3 \pm 1.7$ & $3.5 \pm 0.94$ \\
Alkali treated Fibre:Envirez & & & \\
2 wt\% alk. conc & $1.32 \pm 0.12$ & $45.2 \pm 2.2$ & $54.8 \pm 2.4$ & $6.6 \pm 1.03$ \\
4 wt\% alk. conc & $1.31 \pm 0.17$ & $44.9 \pm 3.1$ & $55.1 \pm 3.1$ & $6.0 \pm 1.09$ \\
8 wt\% alk. conc & $1.32 \pm 0.11$ & $45.0 \pm 2.7$ & $55.0 \pm 2.4$ & $6.3 \pm 1.21$ \\
\hline
\end{tabular}

\begin{tabular}{lllllll}
\hline Solvent (heavy phase) & $\gamma^{\text {tot }}[\mathrm{mN} / \mathrm{m}]$ & $\gamma^{\mathrm{d}}[\mathrm{mN} / \mathrm{m}]$ & $\gamma^{\mathrm{p}}[\mathrm{mN} / \mathrm{m}]$ & $\gamma^{+}[\mathrm{mN} / \mathrm{m}]$ & $\gamma^{-}[\mathrm{mN} / \mathrm{m}]$ & $\gamma^{\mathrm{AB}}[\mathrm{mN} / \mathrm{m}]$ \\
\hline Formamide & 58 & 39 & 19 & 2.28 & 39.6 & 19 \\
Ethylene-glycol & 48 & 29 & 19 & 3 & 30.1 & 19 \\
Water & 72.8 & 21.8 & 51 & 25.5 & 25.5 & 51 \\
Hexadecane & 27.47 & 27.47 & 0 & 0 & 0 & - \\
\hline
\end{tabular}

\begin{tabular}{lllll}
\hline $\begin{array}{l}\text { Sample conditions } \\
\text { (Fibre:Resin=50:50) }\end{array}$ & \multicolumn{3}{l}{ Contact angle $(\theta)$} & \\
\cline { 2 - 5 } & Water & Formamide & Ethylene-glycol & Hexadecane \\
\hline Untreated fibre reinforced composites & & & \\
\multicolumn{1}{l}{ Envirez } & & & \\
AESO & $57.1 \pm 5.0$ & $25.7 \pm 3.6$ & $36.8 \pm 4.2$ & $17.1 \pm 2.0$ \\
MSO & $55.5 \pm 4.7$ & $24.2 \pm 4.9$ & $37.0 \pm 3.8$ & $17.8 \pm 2.2$ \\
MMSO & $64.5 \pm 4.2$ & $32.0 \pm 2.8$ & $43.1 \pm 3.6$ & $19.4 \pm 3.5$ \\
Alkali treated Fibre:Envirez & composites & & $44.0 \pm 3.8$ & $20.6 \pm 2.8$ \\
2 wt\% alk. conc & $53.5 \pm 4.5$ & $33.1 \pm 4.8$ & $31.6 \pm 5.3$ & $19.2 \pm 3.6$ \\
4 wt\% alk. conc & $50.2 \pm 4.9$ & $36.4 \pm 5.0$ & $32.8 \pm 6.8$ & $20.7 \pm 4.2$ \\
8 wt\% alk. conc & $60.7 \pm 3.8$ & $37.4 \pm 4.3$ & $40.2 \pm 5.7$ & $24.3 \pm 5.6$ \\
\hline
\end{tabular}


Fig. 6 Optical microscope images of the tensile fractured specimens; before water absorption a Envirez ${ }^{\mathrm{TM}}$ composites, $\mathbf{b}$ MMSO composites; after water absorption, c Envirez ${ }^{\mathrm{TM}}$ composites, $\mathbf{d}$ MMSO composites
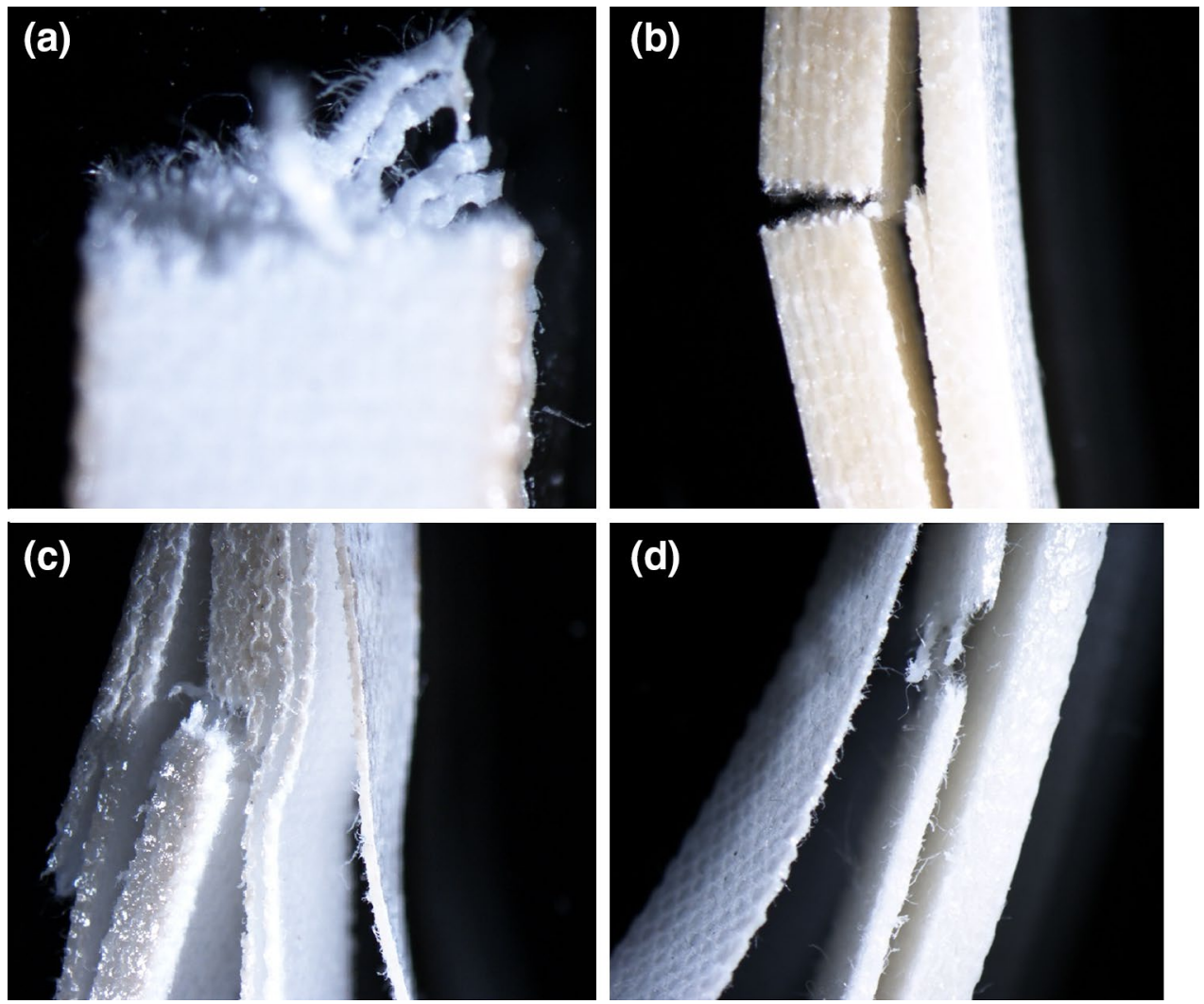

agents. The specimens that were soaked in water before tensile testing behaved differently, and these specimens were also examined. Delamination was more pronounced after water absorption in all composites confirming the low mechanical properties after water absorption. This also confirms the water absorption at the interface.

\section{Conclusions}

The results from this study suggest that these composites from the waste fabric could be used in secondary structural applications. These composites can be compared to natural fibre composites in terms of mechanical properties [4, 22]. Zou et al. also demonstrated the possibility of reusing polyester/cotton blend fabrics as reinforcements for composites [10]. Mechanical properties obtained in this work were better than that of the composites from Zou et al., as thermoset matrices were used [10]. This work shows that discarded cotton/PET fabrics can be used directly without fibre separation or fibre treatment as reinforcements in composites for various applications.

According to Textilia AB (who provided us the recycled cotton/PET), large amount of cotton/PET textiles are disposed of into landfills every year. This not only creates environmental problems but also the loss of PET derived from petroleum resources. In this work, the composites were produced from discarded cotton/PET fabrics in order to find an application for discarded fabrics, as conventional methods to recycle waste fabrics or recover PET are not industrially feasible. Moreover, the energy put into weaving a fabric with high degree fibre alignment will be lost if these fibres were to be separated. Cotton/PET waste fabrics were used as reinforcements in thermoset and thermoplastic composites in our previous work [9]. In this study, the composites from cotton blend fabrics and thermoset bioresins were discussed in order to reuse the cotton/PET fabrics as reinforcements. Industrial production of these composites is possible considering the high amount of textile waste generated every year. The parameters considered for the composite production in this work will be useful in that case. Fibre surface treatment was performed by treating the reinforcement with different alkali concentrations, and this was done in order to improve the fibre-matrix interface. Mechanical properties of the composites were evaluated from tensile, flexural and impact tests. Fibre treatment increased the cost of composite production but the treatment did not improve the mechanical properties of the composites. Due to this reason, the reinforcements can be used directly to produce composites for secondary structural applications. Young's modulus over $10 \mathrm{GPa}$ was obtained when the fabric was used directly without any chemical treatment. Differential scanning calorimetry and thermogravimetric analysis were used to study the thermal 
properties of the composites. Glass transition temperatures of the composites were between 80 and $100^{\circ} \mathrm{C}$, whereas the composites were relatively stable up to $300^{\circ} \mathrm{C}$. Further, the composites were characterised for viscoelastic properties, morphological properties, water absorption, porosity and contact angle. The results fall in line with the several natural fibre reinforced composites $[4,15]$. Recycled cotton/PET show good potential for use in the composite field.

Further investigations of the textile-based composites to enhance the properties may lead to the reuse of the textile fabrics without downgrading. The results recommend that the mechanical properties of the composites should be improved for it to be used as primary structural component. Likewise, the water absorption should be reduced for these composites to be used in humid outdoor environments.

Acknowledgements Textile AB is gratefully acknowledged for supplying the recycled cotton/polyester fabrics.

Open Access This article is distributed under the terms of the Creative Commons Attribution 4.0 International License (http:// creativecommons.org/licenses/by/4.0/), which permits unrestricted use, distribution, and reproduction in any medium, provided you give appropriate credit to the original author(s) and the source, provide a link to the Creative Commons license, and indicate if changes were made.

\section{References}

1. Koronis G, Silva A, Fontul M (2013) Compos Part B-Eng 44:120-127

2. Ahmad F, Choi HS, Park MK (2014) Macromol Mater Eng 300:10-24
3. Fowler PA, Hughes JM, Elias RM (2006) J Food Sci 86:1781-1789

4. Faruk O, Bledzki AK, Fink HP, Sain M (2012) Prog Polym Sci 37:1552-1596

5. Textile O (2010) The fiber year 2009/10. A world survey on textile and nonwovens Industry. 10:1-100.

6. Habib F, Bajpai M (2011) Synthesis and characterization of acrylated epoxidized soybean oil for UN cured coatings.

7. Avila AF, Duarteb MV (2003) Polym Degrad Stabil 80:373-382

8. Shukla SR, Harad AM, Jawale LS (2008) Waste Manage 28:51-56

9. Ramamoorthy SK, Persson A, Skrifvars M (2014) J Appl Polym Sci. doi:10.1002/app.40687

10. Zou Y, Reddy N, Yang Y (2011) Comps Part B-Eng 42:763-770

11. Adekunle K, Ảkesson D, Skrifvars M (2010) J Appl Polym Sci 115:3137-3145

12. Ramamoorthy SK, Skrifvars M, Rissanen M (2015) Cellulose 22:637-654

13. Madsen B, Thygesen A, Lilholt H (2007) Compos Sci Technol 67:1584-1600

14. Behnaz B, Skrifvars M, Rissanen M, Ramamoorthy SK (2014) J Appl Polym Sci 131:1-10

15. Ramamoorthy SK, Skrifvars M, Persson A (2015) Polym Rev 55:107-162

16. Adekunle K, Cho S-W, Ketzscher R, Skrifvars M (2012) J Appl Polym Sci 124:4530-4541

17. Ramamoorthy SK, Kundu CK, Adekunle K, Bashir T, Skrifvars M (2014) J Reinf Plast Comp 33:193-201

18. Esmaeili N, Bakare FO, Skrifvars M, Afshar SJ, Åkesson D (2015) Cellulose 22:603-613

19. Ramamoorthy SK, Di Q, Adekunle K, Skrifvars M (2012) J Reinf Plast Comp 31:1191-1200

20. Ramamoorthy SK, Bakare F, Herrmann R, Skrifvars M (2015) Cellulose 22:2507-2528

21. Åkesson D, Skrifvars M, Seppälä J, Turunen M (2011) J Appl Polym Sci 119:3004-3009

22. Mohanty AK, Misra M, Hinrichsen G (2000) Macromol Mater Eng 276:1-24 